\title{
Indigenous Mechanisms as a Foundation for AfSol Comprehension: Lessons from Gadaa System of the Oromo Nation in Ethiopia
}

\author{
Debela Fituma Mamo ${ }^{\mathrm{i}}$ \\ Department of Civics and Ethical Studies, Faculty of Social Sciences and Humanities, Bule Hora University, Ethiopia
}

Copyright $\mathrm{C} 2017$ by authors, all rights reserved. Authors agree that this article remains permanently open access under the terms of the Creative Commons Attribution License 4.0 International License

\begin{abstract}
The idea of African-led solutions to African security problems has emerged as a holistic political, socio-cultural, economic, and intellectual endeavor to address the peace and security challenges in the continent. Though the term African Solutions for African Problems (AfSol) is coined recently, indigenous conflict management, peacemaking, transitional justice, and reconciliation have existed for much longer in Africa through African indigenous mechanism. This suggests that understanding the features of indigenous African political institutions and social organizations is quite necessary for meaningful development of AfSol. In this regard, Gadaa system which regulates the whole living ways of the Oromo people provides us an invaluable foundation. By organizing, analyzing and interpreting the data obtained from both primary and secondary sources, this study has attempted to examine the key values and principles of the Gadaa system and explore as to how these values and principles can help to achieve the idea of African-led solutions to African challenges. The conclusion up on the research has drawn is that in order to accomplish AfSol's mission as a realistic project, incorporating the principles and values embedded in the Gadaa system is crucial. This research suggests that the integration of Gadaa values and principles into the AfSol pillars, with necessary revisions, would reinforce the latter's practices and help its realization as a policy in the making.
\end{abstract}

Keywords AfSol, Gadaa System, Indigenous, Oromo

\section{Introduction}

Even though African-led solutions for African problems (AfSol) as a policy shift were coined recently, the practices of it were as old as the African people. AfSol is in many ways affiliated to what has been described elsewhere as "Try Africa First" more than three decades ago. Perhaps, the concept connotes a form self-help mechanism which is in fact not a new phenomenon for Africans, where communal self-help system is practiced in many societies and communities in Africa. In this way, the community ensures that everyone is directly and indirectly empowered and in return, they maintain their individual and collective self-reliance and dignity. All things being equal, there would be no need for anyone to seek assistance outside the community to meet basic needs at least, among others. This describes the fact that, Africans have been practicing their own indigenous methods rooted in their culture to deal with their everyday life initially. These indigenous mechanisms emanate from the socio-political, economic, and cultural realities of the Africans, and they have greater relevance than the Eurocentric methods which were externally imposed by the Westerners.

Despite the difficulty of clearly understanding the concept of AfSol objectively, both theoretically and practically, the African-centered theory and methodology might use to describe it partially. Because, this theory primarily considers African studies through critical analysis of African life and culture from the perspective of Africans' themselves (1). Seemingly, AfSol aimed theoretically (at least) to change the life chances of African people based on the underlying concept of home-grown solutions for peace and security problems in the continent. Thus, one way of realizing this AfSol is to rely on African indigenous mechanisms (AIMs) that are practiced by African communities. Among others, these indigenous mechanisms include: Gacaca in Rwanda, Ubuntu in South Africa, Bashingantahe in Burundi, Mato Oput in Northern Uganda, Gadaa System in Oromiya (Ethiopia and Kenya), Magamba in Mozambique, Kpaa Mende in Sierra Leone and etc. The existence of such AIMs probably shows the presence of shared values of Africans amongst themselves which in turn enhances their commitment and ownership to solve the problems they faced based on their own standards despite the varying ways of practice. These African values found at any corner of the 
continent, shared with others or not, are designed as a solution for the people of that locality and also can helps to create a collective identity and social harmony in the continent.

Among these AIMs, Gadaa system is a viable and multipurpose approach which could serve as an alternative foundation of good governance in the African political arena which in turn plays pertinent role to solve peace and security problems. Gadaa System is an indigenous approach where all stakeholders in the system are participated to determine and exercise their ways of life actively. Gadaa system plays important role in governance, peacemaking, conflict management, transitional justice, and reconciliation inter alia by which the Oromos had ruled themselves before they were conquered by the Abyssinian emperors.

Generally, this paper argues, If AfSol is going to be realized practically in Africa with the support of indigenous mechanisms; then the Gadaa System of the Oromo nation in Ethiopia can provide a palatable lesson to that end. As a result, the paper aims to identify the lessons that can be learned from Gadaa System in order to develop the practice of AfSol. Cognizant to this, the paper describes the concept, emergence and purpose of AfSol, and underscores the complementary roles of Gadaa System to the AfSol pillars.

\section{Overviews of the Gadaa System}

Gadaa system is practiced among the Oromo of Ethiopia and Kenya. The term Gadaa has no single and solidly accepted definition as different stakeholders defines it from their own respective fields of study. Gadaa system has been defined from political, philosophical, sociological, anthropological, legal, theological, astronomical, and other points of views (2). This reveals Gadaa system as a comprehensive and multidimensional indigenous practice that can be conceptualized from diverse but complementary perspectives.

The Gadaa system can be discussed as social, political and military institution. Politically, Gadaa system represents a form of government with egalitarian and democratic values where its social organization has been developed in to state under the "Oromo Political Culture" ( 3 p. 42). The system has served as a base of democratic and egalitarian political system and has influenced every aspect of the Oromo's life. Here, election of Gadaa leaders, respecting rule of law, separation and peaceful transition of power, and others are the central guiding principle of the Oromo governance under Gadaa System. Gadaa system has also a considerable importance to military training and service as male youth were trained in the art of warfare that enabled Oromos to emerge as one of the strongest ethno nations in the Horn of Africa between the $12^{\text {th }}$ and mid- $19^{\text {th }}$ centuries (4) and (5). Lewis also noted that, the basic elements of Gadaa system are "republican" in nature where local self-help and self-government through free choice of the Oromo people was used in various sorts of assemblies to discuss and reach on decisions together (6). As a result, elected officials who have specific functions during a limited term of office may be recalled if it deemed necessary by the people. This infers that, the leaders are expected to lead but are also dependent upon the ultimate will of the people. Dirribi Demissie, also described Gadaa system as the mechanism by wich the Oromos are formulating, implemnting, and regulating laws within their jurisdiction where all citizens of the Oromo(and even others may) equally benefited from such legal procedures (7). Moreover, Tena Dewo discusses Gadaa system from moral philosophy point of view, as the system attempts to rationally explain the moral quality of human acts and behaviors in the intricate nature of human relationships (8).

The above discussions reveals, Gadaa system as a multifaceted and holistic system that reveals the political, social, economic, and security aspects of the Oromo people's lives in which they have been governing themselves where the whole community has the opportunities to participate on equal basis in its governance endeavor. It has also a complex and comprehensive institutions that the Oromo people have been inventing since time immemorial to deal with the hurdles and details of their communal lives. These institutions are working as nonviolent methods/elements of conflict resolution, justice administration and peace building. Generally, Gadaa system is an Oromo indigenous mechanism by which the Oromos are shaping their own ways of life and solve any problem they encounter to maintain peace and security of themselves.

\section{Understanding AfSol: Emergence, Meaning and Debates}

\subsection{The Historical Evolution of AfSol}

African-centered solution to African peace and security problems has in it many veins recalling Pan-Africanism and foundations on which the Organization of African Unity (OAU) was formed. In this way, the origin and historic development of AfSol is closely linked to three main chronological achievements in Africa. These are: the Pan-Africanism ideology, the formation of the OAU in 1963, and its transformation into the African Union (AU) in 2002 (9). This implies, any study on the Africanisation of African security necessarily has to begin with the advent of Pan-Africanism and its role in the decolonization process (10).

As the genesis of the AfSol traces back to the Pan-African motives of self-reliance and independence, it strives for African ingenuity and creative imagination to handle peace and security issues overwhelming the continent (11). This entails, Pan-Africanism as aimed to struggle against any exploitation and an endeavor to return to indigenous African concepts both as moral and philosophical assumption (12). 
As a political movement, Pan-Africanism was intended to achieve complete independence of the whole Africa with total rejection of colonialism in all its forms under the "Africa for the Africans" dictum. This shows the relevance of Pan-Africanism to respond to colonialism and neo-colonialism, and create independent and fully liberated Africa. Again, from socio-cultural point of view, Pan-Africanism has served as a symbol of "African renaissance of morale and culture" that quests for African personality to recast African society into its own forms, drawing from its own past, and marrying it to modern ideas (13) p. 38). This makes Pan-Africanism a political and cultural phenomenon which regards Africa, Africans and African descendants as a unit, and aims at the regeneration and unification of Africa and the promotion of a feeling of solidarity among the African people of this world (14). Therefore, Pan-Africanism is aimed to liberate Africans of diverse origins and their descendants by setting aside the cultural differences, by asserting the principality of these shared experiences to promote solidarity and resistance to exploitation.

Moreover, according to the AU Echo Special Edition for the $20^{\text {th }}$ AU Summit in 2013:

Pan-Africanism is an ideology and movement that encourages the solidarity of Africans worldwide. It is based on the belief that unity is vital to economic, social and political progress and aims to "unify and uplift" people of African descent. The ideology asserts that the fates of all African peoples and countries are intertwined. At its core Pan-Africanism is "a belief that African peoples, both on the continent and in the Diaspora, share not merely a common history, but a common destiny". [And therefore] Pan-Africanism stresses the need for a "collective self-reliance."

Generally, the goals of Pan-Africanism were re-examination of African history from an African perspective and a return to African concepts (culture, society and values). Here, Pan-African movement focused primarily on four main pillars. These include: 1) recognizing and uplifting African nationalism against the territorial nationalism built artificially by colonial masters; 2) promoting anti-imperialism agenda; 3) achieving the political movement's goal (independence from colony); and 4) creating Pan-Africanists for African unity on voluntary act that could not be imposed from outside.

Later on, the Organization of African Unity (OAU) was established on 1963 and its foundation marked the conclusion of a long struggle by the Pan-African movement which goes back to the 19th century (15). The Organization was established to promote unity and solidarity of African countries, to defend the sovereignty of members, to eradicate all forms of colonialism, to promote international cooperation, and to coordinate and harmonize member states' policies. However, after about 39 years of existence, OAU was transformed into African Union (AU) as a response to the global demands; where the provisions in its charter neither accommodate nor able to provide the required responses both internally and externally despite some of its achievements (14).

Thus, the OAU was replaced by AU in 2002 with the underlying concepts of "African Ownership and Africanisation" of African peace and security issues (10). This transformation was regarded as a policy shift by which the new organization would become an effective mechanism to deal with the numerous problems afflicting the continent. As a result, the notion of non-interference was replaced with that of non-indifference where member states of the $\mathrm{AU}$ should be concerned with events happening in their neighborhoods though not effective as expected primarily (16).

The preamble of the Constitutive Act of the AU highlighted the ideas of Pan-Africanism, with a renewed desire to seek internal and home-grown solutions to Africa's problems. Specifically, the Peace and Security Architecture attached in the AU and directed by its Peace and Security Council since 2004 stands as the central building block and foundation of AfSol(17). In this line, the then outgoing AU-Commission President Jean Ping stated that "the solutions to African problems are found on the continent and nowhere else" at the AU summit in Addis Ababa in July 2012. The AU structures and its support for the AfSol significantly influenced by the notion of self-reliance by lessening the external interference and forging Africa-owned solutions to Africa's disadvantaged position(18). The notion of AfSol calls for Africa's leaders to unite and assume responsibility and ownership for Africa's future fate based on indigenous/ internal mechanisms with necessary support of external tools.

Currently, Institute for Peace and Security Studies (IPSS) of Addis Ababa University is offering a platform for critical debate on the concept of African-centered Solutions and its practical implications. This mandate was extended to IPSS by the AU Executive Council Decision (AU) (EX.CL/567 (XVI)) under the memorandum of understanding signed between the AU Peace and Security Department and IPSS in 2010 (19). The institute became committed to train, research and promote African ownership by developing approaches that are better adapted to the African realities through different outlets such as preparing workshops and via blog discussions.

\subsection{Understanding AfSol: Meaning, Pillars, and Debate}

Meaning: AfSol as a change in policy orientation to handle peace and security issues in Africa is still foreseeing for clear conceptual definition which might affect its practical application added to other structural and operational problems such as lack of political will and shortage of resources in the continent.

However, there are some perspectives in which AfSol 
have been discussed in the literatures. The concept of AfSol induces a sense of self-reliance and ownership in relation to politics, agency and geography to handle the problems in Africa by Africans themselves (20). This offers Africa a leading role in defining its own problems and providing home-grown solutions to the problems facing the continent based on ownership of working solutions rooted in African identity that is manifested in the realities of the societies (9). But, here one can normally ask if there is a mere African problem that urges African led-solution solely given the contemporary world context where transcontinental security problems are bedeviling the continent and world in general.

To make it clearer, A Concept Note for Workshop Series on African-centered Solutions in Peace and Security conducted on 25 June 2013 by IPSS tries to provide a conceptual framework of AfSol at least. Accordingly, the notion of African-centered solutions includes three dimensions of exploration. These are: 1) African political/ institutional ownership through African Peace and Security Architecture (APSA) and other African institutions to deal with an emerging conflict situations in the continent; 2) African as adapted to a specific local environment where the solutions for conflict should also have to be developed and owned locally by taking into account the context specifics; and 3) African as born out of and adapted to general social characteristics where the specific African identity based on social characteristics of Africa has to be designed.

In addition, as the mandate given to it primarily IPSS held the first workshop on December 26-27, 2014. And according to the report of the workshop, it was reached on consensus that:

AfSol is an ideology that dates back to the time of pan-Africanism; AfSol is a philosophy, which dates back to the Nkrumah's idea of political kingdom; AfSol is a policy in the making which can be practiced and working in progress. Consequently, AfSol is placed in the category of idealism (as an aspiration and desire that reflect an incomplete project but still under work) but with blend of realism (as Africa's collective self-help in peace and security) (19 p. 6).

Generally, based on the adopted research in the two case studies of Somalia and South Sudan the following operational definition of AfSol in peace and security problems of Africa have been suggested (9).

African-led solutions to African challenges in peace and security' can be defined as a holistic political, socio-cultural, economic, and intellectual endeavor, aimed at managing peace and security challenges in Africa at different levels of African political institutions and social organizations. The endeavor is to functionally be owned and undertaken by, and for, the Africans peoples, their institutions, and leadership but in collaboration with the international community.

\begin{abstract}
Most importantly, it is a people- grounded process, enriched by the African traditions, values, beliefs, philosophies and wisdom related to conflict resolutions/management $(9$ p. 84).
\end{abstract}

Pillars: As major practical strategies of doing things on the continent by identifying and mobilizing African intellectual knowledge for guiding principles that define and shape policy, three main pillars AfSol were identified. These pillars include: Commitment, Ownership, and Shared Values (19); p.7). Ownership permits inclusive decision making of all stakeholders in Africa without excessive centralization by leaders added to necessary financial, technical, and material ownership of the solution by all actors at all level. Commitment calls for devotion of all continental institutions, leaders and people at grass-root level, NGOs and others to carry out the responsibility given to them in order to solve problems in the continent. Shared values goes to the (re)formation of geographical collective African identity that encompass solidarity and collective practical solutions to the problems together (Ibid).

Debate on the AfSol: As the definition itself is blurred throughout the literatures, there are two competing lines of arguments reacting to the concept both by supporting and opposing it.

Proponents: Those who support AfSol argue its importance from institutional, relevance and practicability point of view. From institutional point of view; the AU, Regional Economic Communities (RECs) and also Civil Society Organizations (CSOs) are calling for AfSol as efficient and sustainable than the non-African institutions to handel the african problems (9). For example, the then AU's Commissioner for Peace and Security, Ambassador Said Djinnit, in 28 June 2004 remarked that:

No more, never again. Africans cannot watch the tragedies developing in the continent and say it is the UN's responsibility or somebody else's responsibility. We have moved from the concept of non-interference to non-indifference. We cannot as Africans remain indifferent to the tragedy of our people.

In addition, on behalf of the $\mathrm{AU}$, the statement by Frederick Ruhindi at the 12th Assembly of States Parties to the Rome Statute of the International Criminal Court (ICC) Hague, Netherlands 2013 states "we in the African Union strongly believe in African Solutions to African problems." This entails, the presence of these institutions by itself might solve existing problems in Africa. Commenting on how to resolve conflict in the Horn of Africain a sustainable way, Leencho Leta also argued that without indeginous norms and customs of the coexsting society, every rush to conflict resolution would be futile (21). From relevance point of view, George Ayittey argues as many peace agreements in Africa failed because they did not reflect local realities and contexts. He stresses more as the real African solution is the one which is rooted in African culture, tradition, and heritage, though 
the rest of the world have their own share too (22). From existing practical endeavors perspective, the ATMs that exist within African societies can serve as examplar home-grown solutions and the real existence of such indigenous systems can work better than the modernsystem. For example, Gacaca established for the genocide trial in Rwanda is argued as an illustration of the reality (19).

Opponents: From the other side, opponents of the AfSol argues by mentioning different reasons that might encounter its practice realistically. For examples, Eric Blanco and Ferim discussed AfSol as a handicapped doctrine of Africa's International Relations and the fault line in conflict resolution in Africa respectively (23). They contends that the doctrine itself yet is another problem on its own and Africa is not yet capable of resolving its own problems due to the prevalence of insecurity, impunity, poverty and others as actual challenges persistingly exist (23). Musewe also rejects AfSol categorically as the "limited thinking of Africa's leadership" for which AfSol denies Africa the best solutions to its problems (24). Moreover, it is also stressed that both the externally imposed restrictions and the internal limitations in Africa hinders the realization of AfSol (10). Among others they mentioned: lack of political and financial commitment to the principles of AfSol that contrasts starkly with the prevalent rhetoric, the ulterior motives behind the push for AfSol, and the unfinished nature of Africa's self-emancipation as internal challenges. They concluded that the project is "empty rhetoric" which serves as a convenient cover story for African leaders self-interested activities though this undermines some promising attempts made nowadays despite the mentioned hurdels (10 p. 33).

For the purpose of this paper, despite the relevance of opponents argument partly; the presence of AIMs among others can comprehend the realization of AfSol. Thus, this paper is confined to identify the lesson that can be learned from Gadaa System as one of AIMs in order to develop the AfSol's realization in Africa.

\section{Complimentary Roles of the Gadaa System to Enhance the AfSol Pillars}

AfSol is an incongruity between theory and practice. Therefore, the feasibility of AfSol relies on the desirability of what needs to be integrated in the future and what may be relevant to domesticated purposes. As such, the "Oromo democracy is one of those remarkable creation of the human mind that evolved in to a full-fledged system of government. It contains genuinely African solution for some of the problems that democracies everywhere have had face" (2). This statement clearly points out the nature of Gadaa system to provide lesson for AfSol in its realization. Within the AfSol the inclusiveness of each stakeholders to design policy, practice, and evaluate with genuine commitment at all level was mentioned as crucial for promoting good governance through active community participation. In this context,
Gadaa system also provides the mechanisms for inclusive decision making through socialization of leaders (4), and introduces obligations performed by the stakeholders at local, regional, and central level (5). As a result, Gadaa system can assist the realization of AfSol based on the principle of home grown solution and it can be integrated to AfSol principles based on its practices and relevance as follows.

\subsection{Gadaa Grades and Parties: Symbol of Shared Responsibility and Belongingness}

In AfSol, all stakeholders are expected to play their own role at all level and they are expected to build a sense of social identity amongst them. The Gadaa system also designed in a way that its member has the right to participation and performing obligations, where participation was a pre-request to be a member of the society and serve as a symbol of belongingness (3). The Gadaa system of the Oromo people is a system of governance in which people are grouped and organized into five Gadaa parties and govern themselves in rounds by circulating power every eight years. These are: Birmaji, Horata, Michile, Dulo and Robale (the names may be varying from place to place). This serve as multi-party composition in the system and the member of each party could have an opportunity to exercise power once in its life time. Thus, Gadaa system allows positive competition based on consolidated cooperation among these parties for the good will of the whole community. Moreover, the irreversible cycle of power transition give equal chances to all parties and creates higher social bond in the society because it allows for "loyal opposition and a fixed rotative office"(25 p. 84).

The Gadaa system also contains sequential Gadaa grades for the passage of its members. As (26), (27), and (8) discussed it very well, Gadaa system is organized according to age-sets that consist of men who belong to the same genealogical generation. The age-set system was a segmentation that maintains specialization of function along effective lines and organizes the Oromo society into groups that assume different responsibilities in the society every eight years. It harnesses the energies of the youth to the end of the society and gives to each age group a strong awareness of its own status. The same individual assumes different social positions and performs particular duties associated with the various grades.

The ten Gadaa grades include: Gaammee [0-8] -the grade of childhood where the kids are loved and cared for well, IttiMakoo [9-16]- perform light works and starts to learn about life, Dabballe [17-24]- keeping livestock and hunting, Foollee [25-32] -politically significant and nucleus for future Gadaa system, RaabaDoori [33-40] -military wing of Gadaa system, Luba [41-48]-the stage of political and ritual leadership, Yuba [49-56]-plays advisory role in the society, Yuba II [57-64] -the senior advisor, Науyuu [65-72], and Gadamojjii [73-80]-retirement age.

Thus, Gadaa system is an operative method of distributing 
obligation and responsibility across the whole life span and helps the Oromo society in attaining intergenerational equity and separation of powers on a sequential scale. The age-set system provided clear structural reference for members of the society so that the society developed a consistent and stable sense of self and others. The division was part of the entire aspects of their interdependent living. This shows the prevalence of shared obligation and decentralization of every activity within the Oromo society through Gadaa system which increases the sense of ownership and commitment of all stakeholders to effectively play their role within the community.

\subsection{Gadaa System Administrative Structure: Symbol of Separation of Power and Check and Balance}

AfSol as a policy in the making is expected to be fulfilled through democratic governance system where all actors design, implement, and evaluate the policy based on their specializations. Gadaa system is also decentralized social organization where there is no central government and calls for all stakeholders to make decision in their life (3). The power under the Gadaa system was classified both horizontally and vertically within the society and the system is based on the principles of separation of power and shared responsibilities in the overall administration and governance. These include: Caffeel Gumii Gayoo (general assembly), Abbaa Bokku (the father of scepter), Abba Gadaa (the leader directly elected by the mob), Abbaa Duula (chief of the army), Abbaa Seera (judge/ lawyer), Abbaa sa'a (head of economy), and Hadhaa Siqqee (women's cross-cutting power in the Gadaa system). This shows the mechanism through which Gadaa system serve as symbol of decentralization and power sharing mechanism that helps for cooperation and collaboration in the Oromo community. Therefore, Gadaa system promotes rule of law through check and balance among these actors where people have ultimate and final power (popular sovereignty).

\subsection{Gadaa System Institutions: Symbol of Peace Building and Human Security Protection}

The main intention of AfSol is to maintain peace and security of the Africans through locally tailored solutions that fits to the context of the conflicts at hand. The Oromo have a long-standing indigenous mechanism to resolve conflicts and restore peace. The Oromo indigenous conflict resolution mechanism has an important role in restoring peace that has been interrupted by conflict or violence within the communities.

According to (8), Gadaa is system of peace by itself where peacemaking and or building is the central value of the system through its reputable institutions. The features of the Gadaa system serve as premises and conditions for the maintenance and promotion of peace. Especially, in the Gadaa system, supremacy of law and popular sovereignty are unconditionally guaranteed where both the governing and the governed are below the law. As a result, in the Oromo Gadaa system, almost all members of Oromo community participate actively in the promotion and maintenance of peace as the concept of nagaa (peace) in Oromo society shows that Oromo culture is predominantly a culture of peace and this nagaa is defended for all living things. "Alaa manni, sa'aa namni, maatiif waatiin hundi nagayaa?" is the Oromo demands. This literally means peace to the home and neighbors, cows and humans, family and calves, and to all. The Oromo concept of peace is comprehensive in the sense that they belief without peace of maintains, rivers and forests, no peace to humans. There is no one who could be an exception to the law. This shows how far the Oromos are devoted to manage and transform conflict at different levels in their collective lives.

Peacemaking and/or building in the Oromo nation were practiced through different institutions. These institutions, among others include: a) Jarsummaa (elder's council) through which mediators are selected from senior members of the community and the investigation was based on truth finding by making right decision for the issue that the mediation comes in. This has a significant role in promoting a healthy relationship among the community; b) Gumaa (compensation/indemnity) is a mechanism that the Oromo have been using to settle damage of human life and other causalities in terms of cash and/or kind. It is an institution for settling blood feuds and in its firmest sense refers to the mechanism of peace making between conflicting parties. As such, it is a process that brings and strengthens the social cohesion. To this end, (28) expressed gumaa as a viable method of conflict resolution, justice administration and peacemaking/ building. C) Araaara (reconciliation) also strives to bring restorative justice by healing parties involved in conflict both socially and psychologically. Also it works towards family reintegration and strengthens relationships and rebuilds mutual trust between parties involved in conflict.

Besides, the Gadaa system is a system in which human rights and securities are duly respected. For instance: when children are born, it is called Birmadu, which is to mean that they are set free through birth. Thus, according to the Gadaa system, Birmadummaa (freedom) is a natural right in which every person has the inviolable and inalienable right to life and liberty (29).

In the Gadaa system, the fact that human rights are strictly respected has contributed to the prevalence of an outlook of freedom and liberty among the people, to believe in the equality of mankind, and to live harmoniously and peacefully with other ethnic groups. This nature of the Gadaa system has enabled the Oromo people to treat each other and others equally. Even, when a person seeks an asylum among the Oromo people, a ceremony is organized to adopt the person as one of them and, henceforth, such person would have equal rights and obligations among the Oromo community he/she lives with. Guddifachaa (adoption of 
children); Moggasaa (adoption of non-Oromo individuals to Oromo clan); Baallii (peaceful transition of power); and Seera Bоojuu (law of war prisoners) helped to uplift social harmony and promote human security in the Gadaa system. These elements of Gadaa system in turn serve both in Oromo relationships within themselves and with other communities/neighbors to settle conflicts and enhance peace building process which again promotes a sense of shared values with the non-Oromos who wants to live with them.

\subsection{Siiqqee Institution: Symbol of Gender Inclusiveness}

In the realization of AfSol, the active participation of women is highly expected as a part of the African community at large. In the Gadaa system the role of women as part of Oromo community is indispensable and irreducible. According to (30 p. 260), "In all cases without the women's participation there is no Gadaa System. Women are the pillar of the Gadaa system." Asaffa also mentioned the role of women in Gadaa system to maintain the interdependence of men and women peacefully, and to promote moral and ethical order in society (5). Thus, Gadaa system is a system in which the rights of women are respected. In the Gadaa system, the leader, the Abba Gadaa has no deputy. If he dies, it is his wife known as Haadha Golaa who takes the position until the next Gadaa leader elected. The most powerful instrument through which women's rights are duly respected is known as Siiqqee- which is a procedure in which women organize themselves in group to stand up for their rights. In this procedure, women carry a thin stick known as Siiqqee which is given to every girl by her mother up on her wedding day. Women control every movement in the society through this Siiqqee. Therefore, the role of women in Gadaa system is based on Siiqqee institution where women formed a parallel organization of their own excluding men, and this Siiqqee stands for women's ritual, political and social power in the society (3). In Gadaa system, another power women have is ending any act of hostilities whether it is taking place between different clans or with other ethnic groups. Whenever there is conflict going on and women arrive at the place carrying their Siiqqee and stand between the parties at war, both parties promptly give up the fight. Siiqqee serves as a symbol that organizes Oromo women to claim their rights such as political, social, fertility, and others (31 p. 118). Women's Siiqqee institution, sometimes a parallel institution to the Gadaa system "functioned hands in hand with Gadaa system as one of its built-in mechanisms of checks and balances. Thus, the two institutions (Gadaa and Siiqqee) helped to maintain Safuu (moral and ethical order) in Oromo society by enabling Oromo women to have control over resources and private spaces, preserve social status and respect for women, and promotes sisterhood and solidarity by deterring men from infringing upon their individual and collective rights (32). Generally, in the Gadaa rule, women are actively engaged through Siiqqee institution and other institutions to deal with their all aspects of life.

\section{Conclusions}

AfSol entails and retains the Pan-African ideology, concepts and objectives on which the OAU was formed. The transformation of OAU to AU have provided substantive changes to rethinking on how to deal with the peace and security issues in Africa through the lion share of Africans and their institutions themselves. Unlike the OAU, the AU has had to engage in peace and security challenges by installing its principles and institutions where the AfSol concepts, principles, practices and policy are intertwined. Thus, AfSol as a long-term project for peace and development can be understood and conceptualized in relation to promotion of democracy, good governance, peace and security, and inclusive development to address the structural and operational causes of security problems in Africa.

The Gadaa system is a system with a long history by which the people of Oromo have been governing themselves in a democratic way and ensured several values and principles in the living ways of the people. It is an indigenous mechanism of the Oromo people that regulated political system, economic development, social activities, cultural obligations, moral responsibility, and peace and security of the society. It is a well-established and holistic approach that allows popular ownership of every activity, enhances shared responsibility, and promotes a sense of belongingness to lead the whole life of Oromo people. It is based on people-centered democratic principles through separation of power, check and balance, and other mechanisms to promote good governance at its best.

Besides, Gadaa consisted of five-fixed party system in which every Oromo passed through series of grades (associated with various privileges and responsibilities) acquiring various talents and skills. The system made members of the society to accomplish their obligations and enjoy privileges at the right time which in turn promotes ownership, commitment, and shared values amid the Oromos. As Dereje stipulated it, Gadaa system was also highly endowed with moral and legal values, and it created peaceful setting and kept social order by preventing injustice, social evils, and political chaos in the Oromo life (26). Thus, the indigenous values of Gadaa system such as endeavor for self-reliance, tolerance of differences, respect, equality, and others could be viable in modern politics if they are promoted. These values and principles in the system promotes: peaceful transition of political power, complementary multi-party system, respecting human rights including women and children, environmental management, peaceful conflict resolution, mutual assistance, moral obligations, social cohesion and harmony, provision of asylum to seekers, and others which the whole world has been striving to achieve.

The Gadaa system of the Oromo people of Ethiopia and Kenya can be used as exemplar in discussing the roles of all stakeholders which makes them to be committed in their 
ways of life in one way and tie-up them for common goal and destiny on the other. The values and principles of Gadaa system proofs how far the Oromo people have been solving their own problems based on their home-grown approach, and practice have contributed significantly to the efforts of ensuring unity and solidarity among the people. With skillful and careful guidance, Gadaa system would provide extremely useful and powerful building blocks to create and institutionalize a governance system based on the will of the people.

Moreover, the indigenous political leadership of Gadaa System gives a strong emphasis on the rule of law that can shape the moral and political responsibility among leaders if Africa is to enhance the realizations of AfSol. In conclusion, in order to realize the AfSol's vision in the continent; integrating indigenous mechanisms to its pillars serves as milestone. The indigenous leadership of Gadaa system gives a strong emphasis on the rule of law that can handle peace and security issues to enhance the realizations of AfSol. Thus, the Oromo's Gadaa system provides a great lessons for the development of viable AfSol which founded on African indigenous mechanisms as the latter refers to them initially.

\section{REFERENCES}

[1] African-centered Theory and Methodology in Africana Studies: An Introduction. Sekhmet Ra Em and Karanja Keita. 2012, The Journal of Pan African Studies vol.5, no.4, pp. 1-11.

[2] Legesse, Asamrom. Gadaa: Three Approaches to the Study of African Society. NewYork: Free Press, 1973.

[3] OCTB. Gada System: The Politics of Tulama Oromo. Finfinnee: Oromia Culture and Turrism Bureau, 2009.

[4] Gada Values: The Building Blocks of Democratic Oromo Polity. Baissa, Lemmu. USA: Journal of Oromo Studies, 1994. Journal of Oromo Studies (JOS), Volume I Number 2. pp. $17-52$.

[5] The Oromo in Exile: Creating Knowledge and Promoting Social Justice. Jalata, Asafa. 2011, Societies Without Borders 6 (1), pp. 33-72.

[6] Aspects of Oromo Political Culture. Lewis, Herbert. USA: Juornal of Oromo Studies, 1994.

[7] Demissie, Dirribi. Oromo Wisdom in Black Civilization. Finfinnee, Ethiopia: Finfinne Printing and Publication S.C., 2011.

[8] Dewo, Tena. The Concept of Peace in the Oromo Gadaa System: Its Mechanisms and Moral Dimension. 2013, Vol. 15.

[9] Guma Kunda, Abdulahi A. Osman, and Nolawi Melakedingel. Operationalizing African-led Solutions in Peace and Security: Case Studies from South Sudan and Somalia. Addis Ababa, Ethiopia: Institute for Peace and Security Studies (IPSS), and Africa Peace and Security Programme, (APSP)-African-led
Solutions (AfSol) Research Project, 2013.

[10] Who owns African ownership? The Africanisation of security and its limits. Romain Esmenjaud and Benedikt Franke. Geneva: Department of International History and Politics, Graduate Institute of International and Development Studies, 2008, South African Journal of International Affairs, Vol. 15, No. 2, December 2008, pp. 137-158.

[11] AU. OAU/AU@ 50 and Beyond:The Quest for 'African Solutions for African Problems' (ASAP). Pretoria, South Africa: Africa Union, 2014.

[12] OXFAM. African Union Compendium. Addis Ababa, Ethiopia: Oxfam International Liaison Office with the AU, 2012.

[13] Legun, Colin. PAN-AFRICANISM: A Short Political Guied. New York 3, N.Y., U.S.A.: Frederick A. Praeger, Inc., Publishers, 1965.

[14] Omoiya, S. Y. Pan-Africanism, the OAU and the African Union. African Culture and Civilization. 2010, pp. 381-394.

[15] Bujra, Abdalla. AFRICA: FROM THE OAU TO THE AFRICAN UNion. Tripoli, Libya: s.n., 2002.

[16] Kasaija, Apuuli. The Principle of 'African solutions to African Problems' under the Spotlight: The African Union (AU) and the Libya Crisis. s.1.: AfriMap., 2011.

[17] J, Vorrath. Imbalances in the African Peace and Security Architecture: The Current Approach to Capacity-building Needs to Be Challenged. s.1.: Middle East and Africa Research Division, 2012.

[18] L, Bergholm. The African Union, the United Nations and civilian protection. 2010. RSC working paper series NO. 63, $1-35$.

[19] IPSS. African-centred Solutions for Peace and Security (AfSol). Addis Ababa, Ethiopia: Institute for Peace and Security Studies, 2014.

[20] Nathan, Laurie. African Solutions to African Problems: South Africa's Foreign Policy. Prettoria, South Africa: WeltTrends Zeitschrift für internationale Politik 92, 2013.

[21] Lata, Leenco. The Horn of Africa as Common Homeland: The State and Self-Determination in the Era of Heightened Globalization. Waterloo, Ontario, Canada: Wilfrid Laurier University Press, 2004.

[22] African Solutions to African Problems. Ayittey, George. s.1.: Free Africa foundation, 2010.

[23] V, Ferim. African Solutions to African Problems: the Fault Line in Conflict Resolution in Africa. 2012.

[24] Vince, Musewe. The Myth of African solutions to African problems. 2013.

[25] Jemjem Udessa and DhadachaGololcha. The Gadaa Democratic Pluralism: With a Particular Reference to Guji Socio-Cultural and Politico-Legal System. Addis Ababa, Ethiopia: s.n., 2011.

[26] History of Oromo Social Organization: Gadaa Grades Based Roles and Responsibilities. Hinew, Dereje. s.l.: Science, Technology and Arts Research Journal, 2012. July-Sep 2012, 1(3): 88-96.

[27] A Cultural Representation of Women in the ORomo. Hussein, Jeylan W. 2004, African Study Monographs, 25(3) October 
2004, pp. 103-147.

[28] Keneni, Tamene. Exploring Gumaa as an indispensable psycho-social method of conflict resolution and justice administration. Addis Ababa, Ethiopia: s.n., 2013.

[29] ORSCTB. Regarding Sending to you a petition by the Oromo people for the inscription of the Gada System on the Representative List of Intangible Cultural Heritage of Humanity. Addis Ababa: Oromia Regional State Culture and
Tourism Bureau, 2015.

[30] Wabi, Tabor. Partisan Discource and Authentic History. Finfinnee, Ethiopia: s.n., 2015.

[31] The Siiqqee Institution of Oromo Women. Kumsa, Kuwee. s.1.: The Journal ofOromo Studies, 1997. Vol. 4. 1 and 2.

[32] Kumsa, Kuwee. The Siiqqee Institution of Oromo Women. 1997, Vol. 4. 1 and 2.

i Mr. Debela Fituma Mamo is currently a lecturer and researcher at Bule Hora University, Faculty of Social Science and Humanities (Department of Civics and Ethical Studies). He obtained his first degree (BA) in Civics and Ethical Studies from Wollega University (Ethiopia) and second degree (MA) in Peace and Security Studies from Addis Ababa University, Institute of Peace and Security Studies (Ethiopia). His areas of interest for research include: Indigenous Knowledge, Conflict and Peace Studies, Peace Education, Human Security, Gender and Peace and Security among others. 